\title{
Hips With Protrusio Acetabuli Are at Increased Risk for Failure After Femoroacetabular Impingement Surgery: A 10-year Followup
}

\author{
Markus S. Hanke MD, Simon D. Steppacher MD, Corinne A. Zurmühle MD, \\ Klaus A. Siebenrock MD, Moritz Tannast MD
}

Published online: 8 June 2016

(C) The Association of Bone and Joint Surgeons( 2016

\begin{abstract}
Background Protrusio acetabuli is a rare anatomic pattern of the hip in which the femoral head protrudes into the true pelvis. The increased depth of the hip and the excessive size of the lunate surface typically lead to severe pincertype femoroacetabular impingement (FAI); however, to our knowledge, there are no published mid- or long-term studies on results of circumferential acetabular rim trimming through a surgical hip dislocation for patients with this condition.

Questions/purposes (1) What is the 10-year survivorship of the hips treated with circumferential rim trimming through a surgical hip dislocation compared with a control group of hips that underwent surgery for pincer FAI but that did not have protrusio acetabuli? (2) What are the factors that were associated with a decreased likelihood of survivorship in those hips with the following endpoints: total hip arthroplasty, Merle d'Aubigné score of less than 15 , and/or radiographic progression of osteoarthritis (OA)? (3) Does the radiographic pattern of degeneration differ between the two groups?
\end{abstract}

One of the authors (MT) has received funding from the Swiss National Science Foundation.

All ICMJE Conflict of Interest Forms for authors and Clinical

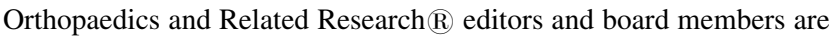
on file with the publication and can be viewed on request. Each author certifies that his or her institution has approved the human protocol for this investigation and that all investigations were conducted in conformity with ethical principles of research.

M. S. Hanke ( $₫)$, S. D. Steppacher, C. A. Zurmühle,

K. A. Siebenrock, M. Tannast

Department of Orthopedic Surgery, Inselspital, University of

Bern, Freiburgstrasse, 3010 Bern, Switzerland

e-mail: markus.hanke@insel.ch
Methods We performed a case-control study comparing two groups: a protrusio group (32 patients [39 hips]) and a control group (66 patients [86 hips]). The control group consisted of hips treated with a surgical hip dislocation for pincer FAI and did not include hips with a positive protrusio sign or a lateral center-edge angle $>39^{\circ}$. The study group did not differ from the control group regarding the preoperative Tönnis OA score, age, and body mass index. However, the study group had more women, decreased mean height and weight, and lower preoperative Merle d'Aubigné-Postel scores, which were inherent differences at the time of first presentation. During the period in question, the indication for performing these procedures was a painfully restricted range of motion in flexion and internal rotation (positive impingement sign). The mean followup of the protrusio group ( $9 \pm 5$ years [range, $2-18$ years]) did not differ from the control group (11 \pm 1 years [range, 10-13 years], $\mathrm{p}=0.109$ ). At the respective minimum followup intervals in the underlying database from which cases and control subjects were drawn, followup was $100 \%$ for patients with protrusion who underwent FAI surgery and $97 \%$ for patients with FAI who underwent surgery for other anatomic patterns (three of 86 hips). We assessed the Merle d'Aubigné-Postel score, Harris hip score, WOMAC, and UCLA activity score at latest followup. A Kaplan-Meier survivorship analysis of the hip was calculated if any of the following endpoints for both groups occurred: conversion to total hip arthroplasty, a Merle d'Aubigné-Postel score $<15$, and/or radiographic progression of OA. Differences in survivorship were analyzed using the log-rank test.

Results At 10-year followup, we found a decreased survivorship of the hip for the protrusio group (51\% [95\% confidence interval $\{\mathrm{CI}\}, 34 \%-67 \%]$ ) compared with the control group (83\% [95\% CI, 75\%-91\%], p < 0.001) with 
one or more of the endpoints stated. We found four multivariate factors associated with a decreased likelihood of survival of the native hip according to the mentioned endpoints: body mass index $>25 \mathrm{~kg} / \mathrm{m}^{2}$ (adjusted hazard ratio, 6.4; 95\% CI, 5.2-8.1; p = 0.009), a preoperative Tönnis OA score $\geq 1(13.3 ; 95 \%$ CI, 11.8-14.9; $\mathrm{p}=0.001)$, a postoperative lateral center-edge angle $>40^{\circ}(4.2 ; 95 \%$ CI, 2.8-5.6; $\mathrm{p}=0.042)$, and a postoperative posterior coverage $>56 \%(6.0 ; 95 \% \mathrm{CI}, 4.3-7.6 ; \mathrm{p}=0.037)$. Preoperatively, joint space narrowing and osteophytes were more frequent posteroinferior (joint space narrowing $18 \%$ versus $2 \%, \mathrm{p}=0.008$; osteophytes $21 \%$ versus $4 \%, \mathrm{p}=$ 0.007 ), medial (joint space narrowing $33 \%$ versus $5 \%, \mathrm{p}<$ 0.001 ) and anterior (osteophytes $15 \%$ versus $1 \%, \mathrm{p}=$ $0.004)$ in the protrusio compared with the control group. After correction in hips with protrusio, progression of joint space narrowing (from $6 \%$ to $45 \%, \mathrm{p}=0.001$ ) and osteophyte formation (from $15 \%$ to $52 \%, \mathrm{p}=0.002$ ) was most pronounced laterally.

Conclusions At 10 years, in 51\% of all hips undergoing open acetabular rim trimming for protrusio acetabuli, the hip can be preserved without further radiographic degeneration and a Merle d'Aubigné score $>15$. Even with the lack of a control group with nonoperative treatment, isolated rim trimming may not entirely resolve the pathomorphology in protrusio hips given the clearly inferior results compared with surgical hip dislocation for FAI without severe overcoverage.

Level of Evidence Level III, therapeutic study.

\section{Introduction}

Protrusio acetabuli is a rare pathologic morphology of the hip in which the femoral head protrudes into the true pelvis [48]. It is a reported cause of hip pain and osteoarthritis in young adults [21]. Radiographically, protrusio acetabuli is defined as the femoral head touching or crossing the ilioischial line on an AP pelvic radiograph (Fig. 1) [17, 44]. The acetabulum usually presents with an excessively increased size of the lunate surface [40], which in turn leads to excessive femoral coverage [44] with a lateral center-edge angle typically exceeding $39^{\circ}$ [12, 47]. Protrusio acetabuli has been described as the most severe representation of pincer-type femoroacetabular impingement (FAI) [18].

Based on these pathomorphological features, one accepted surgical treatment is circumferential acetabular rim trimming through a surgical hip dislocation [18]. To maintain the protective suction seal [8], the often partially ossified labrum in these hips should be reattached, if possible $[17,33]$. This reportedly can lead to superior clinical
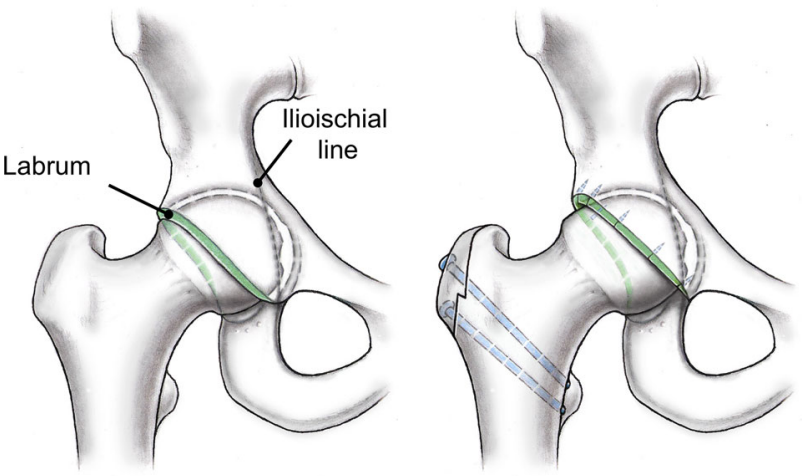

Fig. 1 Protrusio acetabuli is defined by the femoral head crossing or touching the ilioischial line (left). Compared with a normal hip, the size of the lunate surface is increased, which leads to a pincer type of FAI. The rationale of our treatment was to reduce the size of the lunate surface by circumferential rim trimming, if possible with labral refixation or reconstruction (right). Figure created by Klaus Oberli. Reprinted with permission.

results compared with labral resection [7, 16, 27]. In contrast to cam-type labral lesions, labral ossifications are more commonly found in deep hips possibly requiring even labral reconstruction $[33,51]$. The aim of the treatment is to eliminate the FAI conflict by reducing the lunate surface thereby increasing the ROM and potentially decreasing pain (Fig. 1). However, no mid- to long-term followup of this procedure is available. In addition, it is unknown whether these results differ from the treatment of hips with nonprotrusio pincer-type FAI.

We therefore asked: (1) What is the 10-year survivorship of the hips treated with circumferential rim trimming through a surgical hip dislocation compared with a control group of hips that underwent surgery for pincer FAI but that did not have protrusio acetabuli? (2) What are the factors that were associated with a decreased likelihood of survivorship in those hips with the following endpoints: THA, a Merle d'Aubigné-Postel score $<15$, and progression of osteoarthritis? (3) Does the radiographic pattern of degeneration differ between the two groups?

\section{Patients and Methods}

We retrospectively compared the clinical and radiographic outcomes between two different groups undergoing surgical hip dislocation for symptomatic FAI. The local institutional review board approved this study. Between April 1996 and January 2013, we performed 1393 surgical hip dislocations in 1206 patients. Of those, 32 patients (39 hips) were treated for protrusio acetabuli, which was defined by the femoral head touching or crossing the ilioischial line on an AP pelvic radiograph (positive 
protrusio sign [42]). During that period, we consistently performed open circumferential rim trimming through surgical hip dislocation in all 32 patients (39 hips) with protrusio acetabuli. The indication for surgery was a symptomatic pincer-type FAI with a painfully restricted ROM and a positive anterior and/or posterior impingement sign. There were no other previously described surgical procedures performed for protrusio acetabuli during this time period such as a valgus intertrochanteric osteotomy $[17,21]$. Of the 32 patients who were treated with this approach, no patients $(0 \%)$ had died. All patients were available for followup with a minimum of 2 years $(9 \pm 5$ years [range, 2-18 years]). All patients presented with primary protrusio acetabuli. There were no known cases of secondary protrusio acetabuli [21] and no case with open triradiate cartilage. Patients with end-stage osteoarthritis resulting from protrusio acetabuli requiring THA (75 patients [78 hips] for the mentioned study period) were not included in our study group.

The control group consisted of a selection of patients with pincer-type FAI but did not have protrusio acetabuli. These patients were recruited from a previously described group of 121 patients (146 hips) [38] who underwent open surgical hip dislocation for symptomatic FAI between July 2001 and March 2003 with a minimum followup of 10 years. Like with the protrusio group, the indication for surgery was a symptomatic FAI with restricted, painful ROM and a positive anterior impingement test. Of these, we excluded 35 patients ( 37 hips) with secondary FAI after previous surgery (26 femoral/acetabular osteotomies, six open reductions and internal fixation, five in situ pinning after slipped capital femoral epiphysis), 11 patients (12 hips) with Legg-CalvéPerthes disease, seven patients (seven hips) with severe acetabular overcoverage [41] consistent with protrusio acetabuli, and two patients (four hips) with isolated camtype FAI (defined as an alpha angle exceeding $50^{\circ}$ [26]) eventually resulting in a subset of 66 patients ( 86 hips) with idiopathic pincer FAI with or without femoral asphericity. Of those, one patient (one hip) died 8 years postoperatively unrelated to surgery, and two patients (two hips) were lost between 5 and 6 years after surgery. At the time of latest followup, none of these three patients presented with an endpoint (conversion to THA, Merle d'Aubigné-Postel score $<15$, radiographic progression of osteoarthritis) and were included in the survivorship analysis as censored survivors. Eventually, this resulted in a total of 63 patients ( 83 hips) available for followup at a minimum of 10 years $(11 \pm 1$ years [range, 10-13 years]).

At the respective minimum intervals, in the underlying database from which cases and control subjects were drawn, followup was therefore $100 \%$ for patients with protrusio who underwent FAI surgery and $97 \%$ for patients with FAI who underwent surgery for other anatomic patterns (three of 86). As others have found [6, 31, 48], the protrusio group consisted of more women with a proportional decrease in mean height and weight. We also found a lower preoperative Merle d'Aubigné score preoperatively for the study group (Table 1). However, the two groups did not differ in terms of age, body mass index, or the subgroups of Tönnis osteoarthritis score (Table 1).

We performed a power analysis for the primary research question regarding survivorship at 10-year followup with a two-sided level of significance of $5 \%$, beta error of $5 \%$, known survivorship of $80 \%$ [38], an estimated SD of 5\%, and a minimal detectable difference of $5 \%$ resulting in a minimal sample size of 29 hips per group.

Table 1. Demographic data of the patient series

\begin{tabular}{|c|c|c|c|}
\hline Parameters & Protrusio group & Control group & $\mathrm{p}$ value \\
\hline Number of patients (hips) & $32(39)$ & $66(86)$ & \\
\hline Age (years)* & $35 \pm 11(16-54)$ & $32 \pm 8(15-52)$ & 0.089 \\
\hline Sex (percentage male of all hips) & $5(13 \%)$ & $49(57 \%)$ & $<0.001$ \\
\hline Side (percentage right of all hips) & $16(41 \%)$ & $49(57 \%)$ & 0.101 \\
\hline Height $(\mathrm{cm})^{*}$ & $168 \pm 6(159-176)$ & $175 \pm 10(152-204)$ & $<0.001$ \\
\hline Weight $(\mathrm{kg})^{*}$ & $63 \pm 5(55-69)$ & $78 \pm 17(50-145)$ & $<0.001$ \\
\hline Body mass index $\left(\mathrm{kg} / \mathrm{m}^{2}\right)^{*}$ & $24 \pm 4(17-33)$ & $25 \pm 5(18-43)$ & 0.140 \\
\hline Preoperative Merle d'Aubigné score [2]* & $14.4 \pm 1.9(11-17)$ & $15.3 \pm 1.2(10-17)$ & 0.034 \\
\hline Preoperative Tönnis osteoarthritis score $\geq 1$ [46] & $14(36 \%)$ & $19(22 \%)$ & 0.111 \\
\hline Number of hips with Grade 0 (percentage) & $25(64 \%)$ & $67(78 \%)$ & 0.105 \\
\hline Number of hips with Grade 1 (percentage) & $12(31 \%)$ & $17(20 \%)$ & 0.177 \\
\hline Number of hips with Grade 2 (percentage) & $2(5 \%)$ & $2(2 \%)$ & 0.409 \\
\hline Number of hips with Grade 3 (percentage) & $0(0 \%)$ & $0(0 \%)$ & 1 \\
\hline
\end{tabular}

* Mean \pm SD (range); categorical data are expressed as number of hips with percentage in parentheses. 
Table 2. Clinical results preoperative and at followup for the two study groups

\begin{tabular}{|c|c|c|c|c|c|c|c|c|}
\hline \multirow[t]{2}{*}{ Clinical result } & \multicolumn{2}{|l|}{ Protrusio group } & \multicolumn{2}{|l|}{ Control group } & \multirow[t]{2}{*}{ p value* } & \multirow[t]{2}{*}{$\mathrm{p}$ value ${ }^{\dagger}$} & \multirow[t]{2}{*}{ p value } & \multirow[t]{2}{*}{$\mathrm{p}$ value } \\
\hline & Preoperative & Followup & Preoperative & Followup & & & & \\
\hline $\begin{array}{l}\text { Merle d'Aubigné-Postel } \\
\text { score }(18-0)[2]\end{array}$ & $\begin{array}{c}14.4 \pm 1.9 \\
(11-17)\end{array}$ & $\begin{array}{l}15.5 \pm 2.0 \\
\quad(12-18)\end{array}$ & $\begin{array}{l}15.3 \pm 1.2 \\
\quad(10-17)\end{array}$ & $\begin{array}{l}17.0 \pm 1.0 \\
\quad(13-18)\end{array}$ & 0.034 & 0.249 & $<0.001$ & 0.001 \\
\hline Pain (6-0) & $3.2 \pm 1.1(1-5)$ & $4.4 \pm 1.4(1-6)$ & $3.8 \pm 0.7(2-5)$ & $5.2 \pm 0.8(3-6)$ & 0.002 & 0.014 & $<0.001$ & 0.013 \\
\hline Mobility (6-0) & $5.4 \pm 1.0(2-6)$ & $5.6 \pm 0.7(4-6)$ & $5.8 \pm 0.5(4-6)$ & $5.9 \pm 0.3(5-6)$ & 0.115 & 0.178 & 0.421 & 0.064 \\
\hline Walking ability $(6-0)$ & $5.8 \pm 0.4(5-6)$ & $5.7 \pm 0.5(5-6)$ & $5.7 \pm 0.6(2-6)$ & $5.9 \pm 0.3(5-6)$ & 0.513 & 0.091 & 0.201 & 0.068 \\
\hline WOMAC (0-100) [3] & - & $17 \pm 17(0-54)$ & - & $5 \pm 9(0-47)$ & - & - & - & $<0.001$ \\
\hline Pain $(0-100)$ & - & $9 \pm 9(0-25)$ & - & $4 \pm 9(0-50)$ & & & & 0.009 \\
\hline Stiffness $(0-100)$ & - & $6 \pm 5(0-18)$ & - & $7 \pm 11(0-45)$ & & & & 0.214 \\
\hline Function $(0-100)$ & - & $27 \pm 30(0-96)$ & - & $4 \pm 9(0-47)$ & & & & $<0.001$ \\
\hline Harris hip score $(0-100)[11]$ & - & $\begin{array}{l}80 \pm 20 \\
\quad(37-100)\end{array}$ & - & $94 \pm 7(72-100)$ & - & - & - & $<0.001$ \\
\hline SF-12 $[9,50]$ & - & & - & & - & - & - & \\
\hline $\begin{array}{l}\text { Physical Component Scale } \\
(100-0)\end{array}$ & - & $40 \pm 10(24-53)$ & - & $52 \pm 7(24-61)$ & & & & $<0.001$ \\
\hline $\begin{array}{l}\text { Mental Component Scale } \\
(100-0)\end{array}$ & - & $58 \pm 10(21-67)$ & - & $52 \pm 9(33-63)$ & & & & $<0.001$ \\
\hline UCLA score (10-0) [54] & - & $6 \pm 2(3-10)$ & - & $8 \pm 2(3-10)$ & - & - & - & $<0.001$ \\
\hline \multicolumn{9}{|l|}{ ROM (degrees) } \\
\hline Flexion & $\begin{array}{l}96 \pm 13(50- \\
120)\end{array}$ & $\begin{array}{l}102 \pm 9(85- \\
120)\end{array}$ & $\begin{array}{l}102 \pm 11(85- \\
130)\end{array}$ & $\begin{array}{l}101 \pm 10(90- \\
130)\end{array}$ & 0.044 & 0.014 & 0.418 & 0.681 \\
\hline Extension & $1 \pm 2(0-10)$ & $4 \pm 3(0-10)$ & $2 \pm 4(0-20)$ & $4 \pm 3(-10$ to 10$)$ & 0.349 & 0.005 & 0.013 & 0.843 \\
\hline Internal rotation & $15 \pm 12(0-40)$ & $25 \pm 15(0-50)$ & $14 \pm 10(0-45)$ & $20 \pm 11(0-50)$ & 0.897 & 0.004 & $<0.001$ & 0.139 \\
\hline External rotation & $26 \pm 12(0-50)$ & $32 \pm 12(5-55)$ & $29 \pm 11(5-60)$ & $31 \pm 14(5-70)$ & 0.384 & 0.334 & 0.847 & 0.279 \\
\hline Abduction & $30 \pm 11(5-45)$ & $35 \pm 7(25-45)$ & $32 \pm 10(0-60)$ & $44 \pm 11(5-70)$ & 0.983 & 0.484 & $<0.001$ & $<0.001$ \\
\hline Adduction & $19 \pm 7(5-30)$ & $16 \pm 5(0-20)$ & $21 \pm 8(0-35)$ & $21 \pm 6(10-45)$ & 0.4 & 0.398 & 0.616 & $<0.001$ \\
\hline $\begin{array}{l}\text { Anterior impingement test } \\
\text { (percent positive) }\end{array}$ & 100 & 79 & 96 & 35 & 0.36 & 0.022 & $<0.001$ & $<0.001$ \\
\hline $\begin{array}{l}\text { Posterior impingement test } \\
\text { (percent positive) }\end{array}$ & 41 & 16 & 21 & 0 & 0.054 & 0.067 & $<0.001$ & 0.009 \\
\hline
\end{tabular}

Ranges in parentheses; * preoperative between the two study groups; ${ }^{\dagger}$ pre- versus postoperative in the protrusio group; ${ }^{\dagger}$ pre- versus postoperative in the control group; ${ }^{\S}$ postoperative between the two study groups.

The diagnosis of symptomatic anterior FAI for both groups was based on the patient history, clinical examination, and conventional radiography. Anterior FAI was present if the patients had painfully restricted ROM in flexion and internal rotation with typical reproduction of the groin pain.

All patients underwent surgical hip dislocation according to the original technique described by Ganz et al. [10]. A straight incision was made centered over the greater trochanter. After splitting the fascia lata, the interval between the gluteus maximus and medius was developed. In all patients, a digastric trochanteric osteotomy was performed to expose the capsule in the interval between the piriformis and the gluteus minimus muscles. A Z-shaped capsulotomy was used to expose the joint. Full dislocation of the joint was possible after cutting the femoral head ligament. For the protrusio hips, the treatment consisted of circumferential rim trimming and correction of the femoral head-neck offset, if necessary.

In 16 of the 39 protrusio hips, the labrum was refixed with bone anchors, in 21 hips the ossified labrum had to be resected, and two hips underwent labral reconstruction using the femoral head ligament in one case and the fasciae lata in the other. For the FAI hips, the treatment consisted of resection of the femoral head-neck asphericity in case of cam-type FAI. In the presence of a pincer-type deformity, the acetabular rim was segmentally trimmed and the labrum refixed in all cases. There were no additional femoral or acetabular osteotomies performed. Once all corrections were performed with verification of impingement-free ROM, the joint capsule was closed using absorbable sutures. The wound was closed in layers, the greater trochanter reattached with two to three $3.5-\mathrm{mm}$ cortical screws, and a sterile dressing applied. 
Postoperatively, all patients were mobilized using crutches with partial weightbearing of $15 \mathrm{~kg}$ with restricted forced active abduction and passive adduction. Passive continuous motion was used postoperatively for prevention of capsular adhesions. After the early postoperative followups, patients were routinely followed clinically and radiographically after $1,2,5$, and 10 years or at any time on request. The mean followup for the protrusio group did not differ between the protrusio group $(9 \pm 5$ years [range, $2-$ 18 years]) and the control group (11 \pm 1 years [range, 10 13 years], $\mathrm{p}=0.109$ ).

The preoperative clinical evaluation of all patients consisted of an assessment of the full goniometric ROM and the assessment of a positive anterior and/or posterior impingement test [44]. As a result of the nature of the study, different observers assessed these parameters preoperatively, for which substantial inter- and interobserver agreements have been reported previously [19, 22, 53]. At the time of preoperative evaluation, only the Merle d'Aubigné score [2] was assessed as a clinical scoring system. At followup additional clinical scores were assessed using questionnaires by one of us (MSH, not involved in the surgical care of the patients) including the Merle d'Aubigné-Postel score as the main outcome variable. In addition, we assessed the WOMAC [3], the Harris hip score (HHS) [11], the SF-12 Physical and Mental Component Scales $[9,50]$, and the UCLA activity score to provide information for future comparative studies [54] (Table 2).

Patients were evaluated radiographically with an AP pelvic radiograph and a cross-table radiograph according to a standardized technique [44]. One observer (MSH, not involved in the surgical care of the patients) assessed these radiographic images using previously developed and validated software, Hip ${ }^{2}$ Norm (University of Bern) [43, 45, 55]. A total of 13 parameters were assessed and compared between the two groups pre- and postoperatively (Table 3). Osteoarthritis was graded according to Tönnis [46]. To determine the pattern of degeneration, we allocated location of joint space narrowing and osteophyte formation as follows: medial, lateral, concentric, or posteroinferior [36].

We tested normal distribution using the KolmogorovSmirnov test. Pairwise comparison of demographic,

Table 3. Pre- and postoperative radiographic data

\begin{tabular}{|c|c|c|c|c|c|c|c|c|}
\hline \multirow[t]{2}{*}{ Parameters } & \multicolumn{2}{|l|}{ Protrusio group } & \multicolumn{2}{|l|}{ Control group } & \multirow{2}{*}{$\begin{array}{l}\mathrm{p} \\
\text { value* }\end{array}$} & \multirow{2}{*}{$\begin{array}{l}\mathrm{p} \\
\text { value }^{\dagger}\end{array}$} & \multirow{2}{*}{$\begin{array}{l}\mathrm{p} \\
\text { value }\end{array}$} & \multirow{2}{*}{$\begin{array}{l}\mathrm{p} \\
\text { value }^{\S}\end{array}$} \\
\hline & Preoperative & Postoperative & Preoperative & Postoperative & & & & \\
\hline $\begin{array}{l}\text { Lateral center-edge angle } \\
\text { (degrees) [52] }\end{array}$ & $51 \pm 10(28-71)$ & $40 \pm 6(30-65)$ & $28 \pm 5(18-39)$ & $24 \pm 6(10-44)$ & $<0.001$ & $<0.001$ & $<0.001$ & $<0.001$ \\
\hline $\begin{array}{l}\text { Acetabular index } \\
\text { (degrees) [46] }\end{array}$ & $\begin{array}{l}-12 \pm 6 \\
\quad(-21 \text { to } 4)\end{array}$ & $\begin{array}{l}-7 \pm 6 \\
\quad(-21 \text { to } 5)\end{array}$ & $\begin{array}{l}4 \pm 5 \\
\quad(-8 \text { to } 17)\end{array}$ & $\begin{array}{l}8 \pm 6 \\
\quad(-5 \text { to } 25)\end{array}$ & $<0.001$ & $<0.001$ & $<0.001$ & $<0.001$ \\
\hline $\begin{array}{l}\text { Extrusion index } \\
\text { (percent) [24] }\end{array}$ & $4 \pm 7(-13$ to 21$)$ & $13 \pm 5(-3$ to 22$)$ & $22 \pm 5(12-32)$ & $27 \pm 6(11-39)$ & $<0.001$ & $<0.001$ & $<0.001$ & $<0.001$ \\
\hline ACM angle (degrees) $[4,13]$ & $45 \pm 4(36-53)$ & $45 \pm 5(37-55)$ & $44 \pm 4(33-55)$ & $44 \pm 6(34-56)$ & 0.529 & 0.037 & 0.125 & 0.112 \\
\hline $\begin{array}{l}\text { Crossover sign (percent } \\
\text { positive) [28] }\end{array}$ & 25 & 26 & 73 & 35 & $<0.001$ & 0.953 & $<0.001$ & 0.386 \\
\hline $\begin{array}{l}\text { Retroversion index [44] } \\
\text { (percent, of hips with } \\
\text { positive crossover sign [28]) }\end{array}$ & $18 \pm 11(2-37)$ & $15 \pm 8(3-31)$ & $24 \pm 15(1-53)$ & $10 \pm 10(1-48)$ & 0.271 & 0.174 & $<0.001$ & 0.185 \\
\hline $\begin{array}{l}\text { Posterior wall sign (percent } \\
\text { positive) [28] }\end{array}$ & 3 & 16 & 85 & 87 & $<0.001$ & 0.056 & 0.714 & $<0.001$ \\
\hline Sharp angle (degrees) [32] & $36 \pm 4(26-46)$ & $40 \pm 4(32-46)$ & $39 \pm 3(33-47)$ & $40 \pm 3(33-47)$ & 0.001 & $<0.001$ & 0.008 & 0.721 \\
\hline Ischial spine sign (percent) [14] & 24 & 21 & 46 & 48 & 0.033 & 0.690 & 0.828 & 0.005 \\
\hline $\begin{array}{l}\text { Caudocranial coverage } \\
\text { (percent) }\end{array}$ & $93 \pm 6(75-100)$ & $86 \pm 8(63-100)$ & $80 \pm 7(64-93)$ & $73 \pm 8(51-91)$ & $<0.001$ & $<0.001$ & $<0.001$ & $<0.001$ \\
\hline Anterior coverage (percent) & $40 \pm 10(22-61)$ & $34 \pm 8(17-46)$ & $24 \pm 6(11-37)$ & $17 \pm 5(8-35)$ & $<0.001$ & $<0.001$ & $<0.001$ & $<0.001$ \\
\hline Posterior coverage (percent) & $72 \pm 11(48-95)$ & $63 \pm 10(43-92)$ & $41 \pm 7(27-64)$ & $41 \pm 8(22-64)$ & $<0.001$ & $<0.001$ & 0.621 & $<0.001$ \\
\hline $\begin{array}{l}\text { Axial alpha angle (degrees) } \\
{[26]}\end{array}$ & $53 \pm 10(40-79)$ & $45 \pm 6(34-58)$ & $\begin{array}{l}62 \pm 12(37- \\
85)\end{array}$ & $46 \pm 7(30-65)$ & $<0.001$ & $<0.001$ & $<0.001$ & 0.300 \\
\hline
\end{tabular}

Ranges shown in parentheses; $*$ preoperative between the two study groups; ${ }^{\dagger}$ pre- versus postoperative in the protrusio group; ${ }^{*}$ pre- versus postoperative in the control group; ${ }^{\S}$ postoperative between the two study groups; ACM = angle of Idelberger and Frank. 
intraoperative, and radiographic data was performed using the Wilcoxon test for paired data (pre- and postoperative data) and the Mann-Whitney U-test for unpaired data (between the two study groups). The frequency of demographic and radiographic data was compared using the Fisher's exact test. Survival of surgery was calculated with the method of Kaplan and Meier [15] using the following three endpoints: conversion to THA, radiographic progression of osteoarthritis, and/or a fair Merle d'Aubigné score (less than 15) [38, 39]. Predictive factors for failure were calculated using the univariate and multivariate Cox

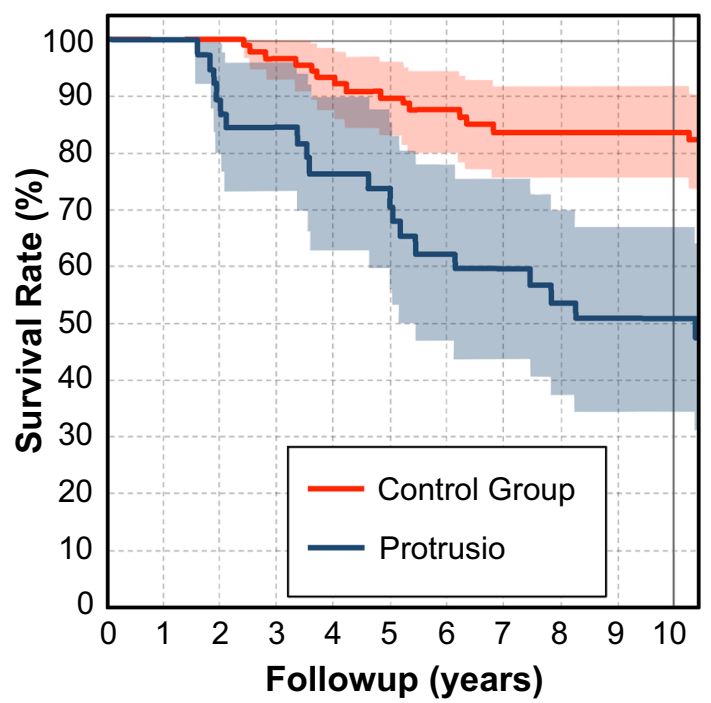

Fig. 2 The cumulative survivorship at 10 years for protrusio hips treated with circumferential trimming was $51 \%$ (95\% CI, 34\%-67\%) compared with hips with classic FAI with (83\%; 95\% CI, 75\%-91\%; p $<0.001)$. Endpoints were defined as conversion to THA, progression of osteoarthrosis, and a Merle d'Aubigné-Postel score $<15$. proportional model with corresponding hazard ratios and adjusted hazard ratios [5]. Hazard ratios were calculated with $95 \%$ confidence intervals (CIs).

\section{Results}

At 10-year followup, we found decreased survivorship of the hip for the protrusio group (51\% [95\% CI, 34\%-67\%]) compared with the control group (83\% [95\% CI, 75\%$91 \%$ ], $\mathrm{p}<0.001)$ with one or more the endpoints stated (Fig. 2). In the protrusio group, 29 hips (74\%) reached an endpoint including 12 hips with conversion to THA, eight hips with progression of osteoarthrosis, and nine hips with a Merle d'Aubigné-Postel score $<15$ at latest followup. In the control group, 17 hips $(20 \%)$ reached an endpoint including nine hips with conversion to THA, seven hips with progression of osteoarthrosis, and one hip with a Merle d'Aubigné-Postel score $<15$ points at latest followup.

We found four multivariate and four univariate factors associated with a decreased likelihood of survival of the native hip according to the mentioned endpoints: two demographic, three preoperative, and three postoperative radiographic factors (Table 4 ). The multivariate predictors were a body mass index $>25 \mathrm{~kg} / \mathrm{m}^{2}$ (adjusted hazard ratio, 6.4; 95\% CI, 5.2-8.1; $\mathrm{p}=0.009$ ), a preoperative Tönnis osteoarthritis score [46] $\geq 1(13.3 ; 95 \%$ CI, $11.8-14.9 ; \mathrm{p}=$ $0.001)$, a postoperative lateral center-edge angle [52] $>40^{\circ}$ (4.2; 95\% CI, 2.8-5.6; $\mathrm{p}=0.042)$, and a postoperative posterior coverage $>56 \%(6.0 ; 95 \% \mathrm{CI}, 4.3-7.6 ; \mathrm{p}=$ 0.037). The univariate predictors were age at operation $>47$ years (hazard ratio, $5.1 ; 95 \% \mathrm{CI}, 3.7-6.4 ; \mathrm{p}=0.016$ ),

Table 4. Predictive factors for failure with corresponding hazard ratios

\begin{tabular}{|c|c|c|c|c|}
\hline \multirow[t]{2}{*}{ Predictive factor } & \multicolumn{2}{|l|}{ Univariate } & \multicolumn{2}{|l|}{ Multivariate } \\
\hline & Hazard ratio* & $\mathrm{p}$ value & Hazard ratio* & $\mathrm{p}$ value \\
\hline \multicolumn{5}{|l|}{ Demography } \\
\hline Age $>47$ years & $5.1(3.8-6.4)$ & 0.016 & & \\
\hline $\mathrm{BMI}>25 \mathrm{~kg} / \mathrm{m}^{2}$ & $5.1(3.8-6.3)$ & 0.011 & $6.4(5.2-8.1)$ & 0.009 \\
\hline \multicolumn{5}{|l|}{ Preoperative factors } \\
\hline LCE angle $>50^{\circ}[52]$ & $5.1(3.5-6.6)$ & 0.040 & & \\
\hline Sharp angle $<34^{\circ}[32]$ & $4.9(3.7-6.1)$ & 0.012 & & \\
\hline Osteoarthritis $\geq$ Tönnis Grade 1 [46] & $12.0(10.5-13.6)$ & 0.002 & $13.3(11.8-14.9)$ & 0.001 \\
\hline \multicolumn{5}{|c|}{ Postoperative factors related to surgical accuracy } \\
\hline LCE angle $>40^{\circ}[52]$ & $4.7(3.5-5.9)$ & 0.009 & $4.2(2.8-5.6)$ & 0.042 \\
\hline Acetabular index $<-8^{\circ}[46]$ & $2.5(1.7-3.3)$ & 0.024 & & \\
\hline Posterior coverage $>56 \%$ & $3.5(2.4-4.5)$ & 0.027 & $6.0(4.3-7.6)$ & 0.037 \\
\hline
\end{tabular}

* Mean \pm SD (range); endpoints were defined as conversion to THA, radiographic progression of osteoarthritis, and/or a

Merle d'Aubigné-Postel score less than 15 points; BMI = body mass index; LCE = lateral center-edge. 
a preoperative lateral center-edge angle [52] $>50^{\circ}(5.1$; 95\% CI, 3.5-6.6; $\mathrm{p}=0.040)$, a preoperative Sharp angle [32] $<34^{\circ}(4.9 ; 95 \% \mathrm{CI}, 3.7-6.1 ; \mathrm{p}=0.012)$, and a postoperative acetabular index [46] $<-8^{\circ}(2.5 ; 95 \%$ CI, $1.7-$ $3.3 ; p=0.024)$. Labral refixation was not a predictor.
The main preoperative difference in the pattern of osteoarthritis between the two study groups was the increased frequency of both joint space narrowing and osteophyte formation medially and posteroinferior in the protrusio group (Fig. 3). After correction in hips with

Table 5. Patterns of osteoarthritis preoperatively and at most recent followup for the two study groups

\begin{tabular}{|c|c|c|c|c|c|c|c|c|}
\hline \multirow[t]{2}{*}{ Pattern of osteoarthritis } & \multicolumn{2}{|l|}{ Protrusio } & \multicolumn{2}{|l|}{ Control group } & \multirow[t]{2}{*}{$\mathrm{p}$ value* } & \multirow[t]{2}{*}{$\mathrm{p}$ value ${ }^{\dagger}$} & \multirow[t]{2}{*}{ p value } & \multirow[t]{2}{*}{$\mathrm{p}$ value $^{\mathrm{s}}$} \\
\hline & Preoperative & Followup & Preoperative & Followup & & & & \\
\hline \multicolumn{9}{|c|}{ Joint space narrowing (percent positive) } \\
\hline Lateral & 6 & 45 & 10 & 22 & 0.37 & $<0.001$ & 0.03 & 0.019 \\
\hline Medial & 33 & 35 & 5 & 11 & $<0.001$ & 0.671 & 0.143 & 0.004 \\
\hline Concentric & 0 & 0 & 2 & 3 & 0.486 & 1 & 0.644 & 0.496 \\
\hline Posteroinferior & 18 & 19 & 2 & 13 & 0.008 & 0.555 & 0.008 & 0.885 \\
\hline \multicolumn{9}{|c|}{ Osteophyte formation (percent positive) } \\
\hline \multicolumn{9}{|l|}{ Femoral } \\
\hline Lateral & 26 & 39 & 6 & 17 & 0.004 & 0.215 & 0.035 & 0.015 \\
\hline Anterior & 15 & 23 & 1 & 8 & 0.008 & 0.309 & 0.042 & 0.051 \\
\hline Foveal & 12 & 23 & 2 & 11 & 0.062 & 0.203 & 0.032 & 0.13 \\
\hline Posteroinferior & 21 & 32 & 4 & 13 & 0.007 & 0.216 & 0.042 & 0.02 \\
\hline \multicolumn{9}{|l|}{ Acetabular } \\
\hline Lateral acetabular edge & 15 & 52 & 5 & 25 & 0.085 & 0.002 & $<0.001$ & 0.009 \\
\hline Saber tooth $[20]$ & 6 & 29 & 6 & 19 & 0.659 & 0.014 & 0.012 & 0.284 \\
\hline
\end{tabular}

All values are expressed as percentages; * preoperative between the two study groups; †preoperative versus followup status in the protrusio group; ${ }^{\dagger}$ preoperative versus followup status in the control group; ${ }^{\S}$ between the two study groups at the most recent followup status.

Joint Space Narrowing
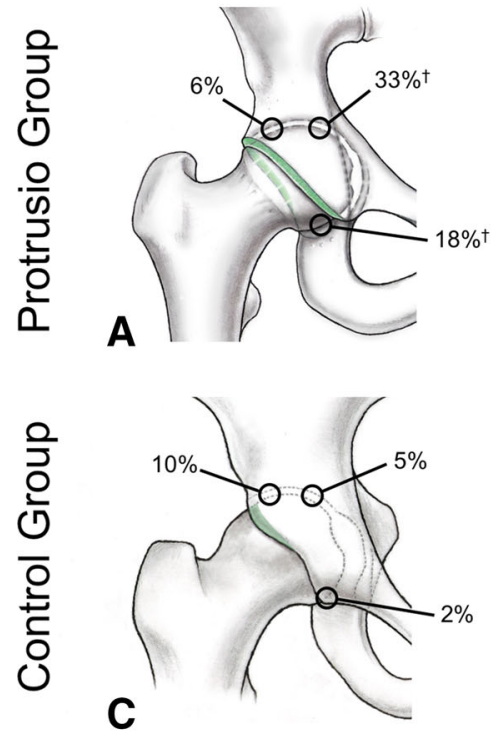

Preoperative
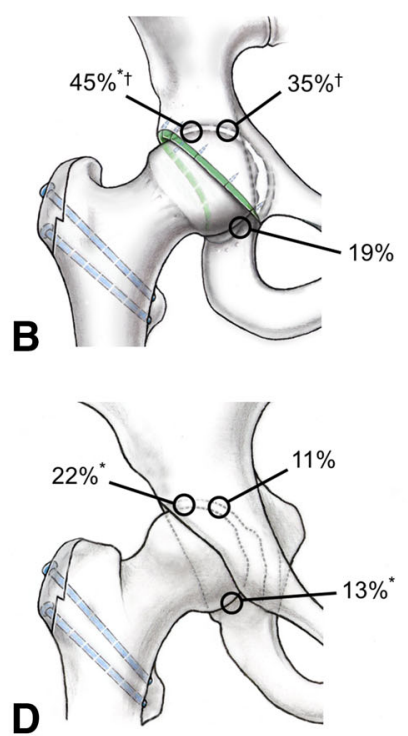

Followup

Fig. 3A-H The patterns of degeneration including joint space narrowing (A-D) and osteophyte formation $(\mathbf{E}-\mathbf{F})$ are shown for protrusio hips $(\mathbf{A}, \mathbf{B}, \mathbf{E}, \mathbf{F})$ and classic FAI $(\mathbf{C}, \mathbf{D}, \mathbf{G}, \mathbf{H})$. Both preoperative joint degeneration $(\mathbf{A}, \mathbf{C}, \mathbf{E}, \mathbf{G})$ and degenerative

\section{Osteophyte Formation}
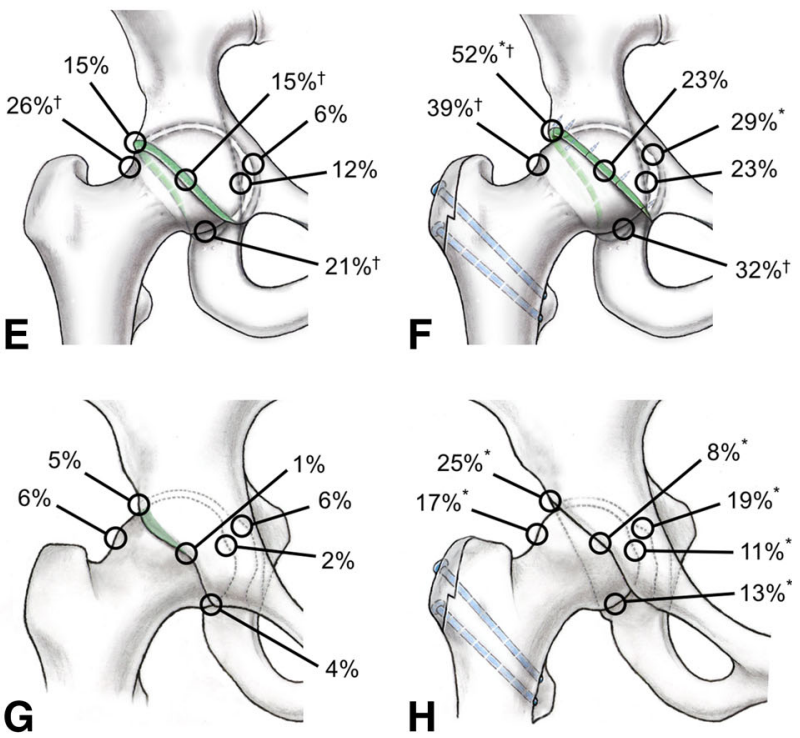

Preoperative

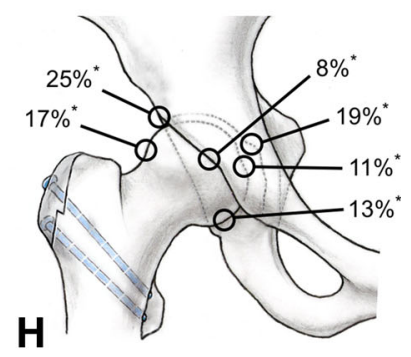

Followup

changes at followup are shown $(\mathbf{B}, \mathbf{D}, \mathbf{F}, \mathbf{H}) . *$ Significant difference pre- versus postoperative; ${ }^{\dagger}$ significant difference between the two study groups. 

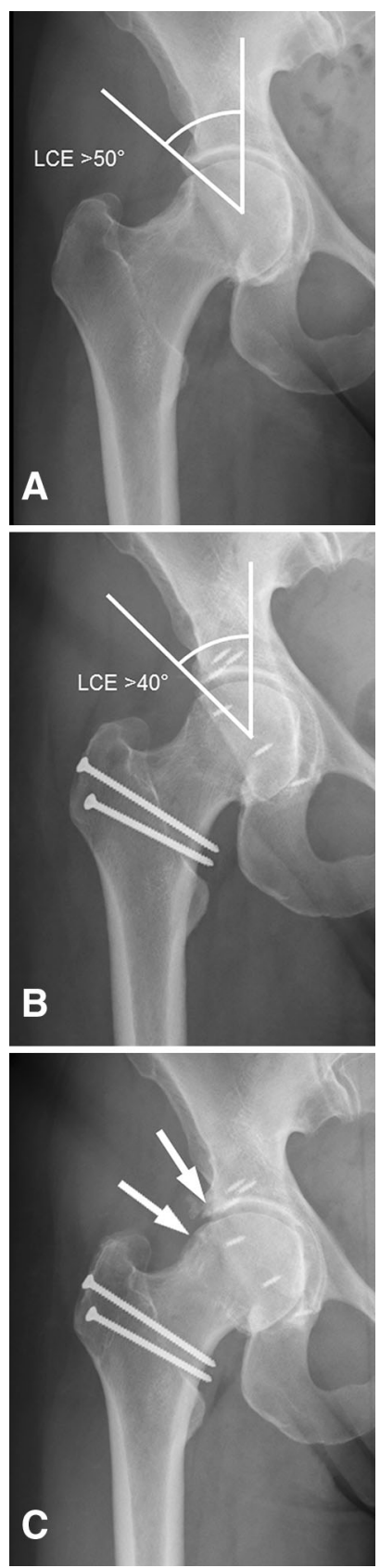

Fig. 4A-C Right hip of a 40-year-old woman with acetabular protrusio with (A) preoperative medial joint space narrowing, minimal osteophytes at the femoral head, and a lateral center-edge (LCE) angle of $>50^{\circ}$. The patient underwent surgical hip dislocation (B) with circumferential rim trimming and labral reattachment. Postoperatively a LCE angle of $>40^{\circ}$ was persistent. (C) Four years after the operation, the hip presented with osteoarthritic changes with osteophyte formation and lateral joint space narrowing.

protrusio, progression of joint space narrowing and osteophyte formation was most pronounced laterally (Fig. 3). In more detail, joint space narrowing and osteophytes were more frequent in the protrusio group compared with the control group at the following locations: joint space narrowing medial $(33 \%$ versus $5 \%$; $p<0.001)$ and posteroinferior $(18 \%$ versus $2 \% ; \mathrm{p}=0.008)$ and osteophytes at the lateral $(26 \%$ versus $6 \% ; \mathrm{p}=0.004)$, anterior $(15 \%$ versus $1 \% ; \mathrm{p}=0.008)$, and posteroinferior $(21 \%$ versus $4 \% ; \mathrm{p}=0.007$ ) femoral head (Table 5). Joint space narrowing progressed laterally in both groups (from 6\% to $45 \%$ in the protrusio group, $\mathrm{p}=0.001$; from $10 \%$ to $22 \%$ in the control group, $\mathrm{p}=0.030$ ) and posteroinferior only in the control group (from $2 \%$ to $13 \%, p=0.008$; Fig. 3). At followup, lateral joint space narrowing was more frequent in the protrusio group ( $45 \%$ versus $22 \%, \mathrm{p}=0.019$ ) despite progression in both groups (Table 5). Medial joint space narrowing remained more frequent in the protrusio group ( $35 \%$ versus $11 \%, p=0.004$; Fig. 3 ). In the protrusio group, progression of saber tooth osteophytes [23] (from $6 \%$ to $29 \%, \mathrm{p}=0.014)$ and osteophytes at the lateral acetabular edge (from $15 \%$ to $52 \%, \mathrm{p}=0.002$ ) was found. In the control group, osteophytes at all locations progressed ( $p$ ranging from $<0.001$ to 0.042 ; Table 5). At most recent followup, osteophytes were more frequent in the protrusio group at the lateral femoral head $(39 \%$ versus $17 \%, \mathrm{p}=$ $0.015)$ and the posteroinferior femoral head (32\% versus $13 \%, \mathrm{p}=0.020)$ as well as the lateral acetabular edge $(52 \%$ versus $25 \%, \mathrm{p}=0.009$; Fig. 3 ).

\section{Discussion}

Protrusio acetabuli is a pathology in which the femoral head protrudes into the true pelvis. In association with the increased depth of the acetabulum, the size of the lunate surface is excessive, which can result in pincer-type FAI. One approach to treat this condition is circumferential rim trimming. The first anecdotal report of such a technique was performed by Smith-Peterson in 1936 [35]. However, the development in recent years of techniques to safely dislocate the hip has offered more reproducible methods for this treatment concept and have been routinely used as surgical treatment for protrusio acetabuli in our department since April 1996. We asked if patients with protrusio acetabuli can profit from an acetabular rim trimming in long-term followup. We found that after 10 years $51 \%$ of all cases undergoing open acetabular rim trimming for protrusio acetabuli can be preserved without further degeneration.

This study has several limitations. First, our two study groups were not entirely comparable regarding sex, height, weight, and preoperative Merle d'Aubigné-Postel score (Table 1). We had a higher percentage of women in the protrusio group, which is an inherent demographic factor for protrusio hips. This might influence our followup results because others have suggested that women do not do as well with FAI surgery as men do [25, 34]. The differences of height and weight can be explained by the 
Table 6. Selected literature on treatment of hips with protrusion

\begin{tabular}{|c|c|c|c|c|c|}
\hline Author & Year & Treatment & $\begin{array}{l}\text { Number of } \\
\text { hips (number } \\
\text { of patients) }\end{array}$ & $\begin{array}{l}\text { Followup } \\
\text { (years) }\end{array}$ & Results \\
\hline $\begin{array}{l}\text { Smith- } \\
\quad \text { Petersen } \\
{[35]}\end{array}$ & 1936 & Open acetabuloplasty & $1(1)$ & 0.8 & $\begin{array}{l}\text { Case report of a 55-year-old woman with hip protrusio } \\
\text { who underwent acebuloplasty resulting in decreased } \\
\text { pain and improved ROM at a short-term followup }\end{array}$ \\
\hline $\begin{array}{l}\text { Viernstein } \\
\text { et al. [49] }\end{array}$ & 1970 & $\begin{array}{l}\text { Valgus and medializing } \\
\text { intertrochanteric osteotomy, } \\
\text { tenotomy of hip muscles }\end{array}$ & $\begin{array}{l}14 \text { (9) with } \\
\text { osteotomy } \\
20 \text { (12) with } \\
\text { tenotomy }\end{array}$ & NA & $\begin{array}{l}\text { Decreased pain and improved ROM in the majority of } \\
\text { hips after valgus and medializing intertrochanteric } \\
\text { osteotomy; best result in young patients }(<35 \text { years } \\
\text { with limited osteoarthrosis; the technique with hip } \\
\text { muscle release to reduce muscular tension on the join } \\
\text { was abandoned as a result of poor results }\end{array}$ \\
\hline $\begin{array}{l}\text { Hooper and } \\
\text { Jones } \\
\text { [12] }\end{array}$ & 1971 & $\begin{array}{l}\text { Femoral osteotomy, acetabuloplasty, } \\
\text { drilling, fusion of the hip, } \\
\text { Girdlestone, hip replacement }\end{array}$ & NA (59) & NA & $\begin{array}{l}\text { A series of } 59 \text { hips with conservative treatment in } 36 \\
\text { hips and operative treatment in } 23 \text { hips; in older } \\
\text { patients with protrusion, the THA revealed the best } \\
\text { results regarding pain and function; no statement } \\
\text { regarding operative treatment of younger patients was } \\
\text { formulated }\end{array}$ \\
\hline $\begin{array}{l}\text { Rosemeyer } \\
\text { et al. [29] }\end{array}$ & 1973 & $\begin{array}{l}\text { Valgus and medializing } \\
\text { intertrochanteric osteotomy }\end{array}$ & $25(15)$ & $1-6$ & $\begin{array}{l}\text { Followup study of the intertrochanteric osteotomy } \\
\text { according to Viernstein et al [43]; the valgus and } \\
\text { medializing intertrochanteric osteotomy resulted in } \\
\text { decreased pain and improved ROM; the best results } \\
\text { were found in the patient group with an average age } \\
\text { of } 35 \text { years; in patients aged } 60 \text { years and older, the } \\
\text { benefit was only little }\end{array}$ \\
\hline $\begin{array}{l}\text { Verburg } \\
\text { and } \\
\text { Elzenga } \\
\text { [48] }\end{array}$ & 1978 & Valgus intertrochanteric osteotomy & $8(6)$ & 3 (mean) & $\begin{array}{l}\text { The goal of surgery was a more cranial resultant force to } \\
\text { reduce the pressure toward the floor of the } \\
\text { acetabulum; after surgery, hip function was increased } \\
\text { pain decreased, and walking was increased and } \\
\text { unlimited in } 4 \text { of } 6 \text { hips; best results were found in } \\
\text { hips without osteoarthritic changes }\end{array}$ \\
\hline Steel [37] & 1996 & Closure of the triradiate physis & $21(11)$ & $\begin{array}{l}\text { NA (until } \\
\text { skeletal } \\
\text { maturity) }\end{array}$ & $\begin{array}{l}\text { Marfan syndrome is associated with hip protrusio; a } \\
\text { technique for closure of the triradiate physis is } \\
\text { presented to treat hips in patients with Marfan } \\
\text { syndrome; performed in children up to the age of } 10 \\
\text { years, this procedure has the potential to stop or } \\
\text { reverse hip protrusio and symptoms relieved; in older } \\
\text { patients, symptoms can still be relieved but } \\
\text { radiographic improvement is unlikely }\end{array}$ \\
\hline $\begin{array}{l}\text { McBride } \\
\text { et al. [21] }\end{array}$ & 2001 & Valgus intertrochanteric osteotomy & $19(12)$ & $2-33$ & $\begin{array}{l}\text { Series of protrusio hips that underwent valgus } \\
\text { intertrochanteric osteotomy with an additional closure } \\
\text { of the triradiate physis in one skeletally immature hip } \\
\text { valgus intertrochanteric osteotomy should not be } \\
\text { performed in patients aged older than age } 40 \text { years or } \\
\text { hips with degenerative changes; in addition, } \\
\text { preoperative limited ROM was associated with an } \\
\text { unsatisfactory result; THA after intertrochanteric } \\
\text { osteotomy showed no inferior results compared with } \\
\text { primary THA }\end{array}$ \\
\hline $\begin{array}{l}\text { Leunig } \\
\quad \text { et al. [17] }\end{array}$ & 2009 & $\begin{array}{l}\text { Acetabular rim trimming, valgus } \\
\text { intertrochanteric osteotomy and } \\
\text { reversed PAO }\end{array}$ & $22(12)$ & $1-7$ & $\begin{array}{l}\text { A more tailored surgical treatment of protrusio hips is } \\
\text { recommended; surgical hip dislocation with trimming } \\
\text { of the acetabular rim with an optional valgus } \\
\text { intertrochanteric osteotomy is the treatment of } \\
\text { choice; in hips with extension of the acetabular fossa } \\
\text { in the weightbearing zone, a reversed PAO is } \\
\text { indicated }\end{array}$ \\
\hline
\end{tabular}


Table 6. continued

\begin{tabular}{|c|c|c|c|c|c|}
\hline Author & Year & Treatment & $\begin{array}{l}\text { Number of } \\
\text { hips (number } \\
\text { of patients) }\end{array}$ & $\begin{array}{l}\text { Followup } \\
\text { (years) }\end{array}$ & Results \\
\hline $\begin{array}{c}\text { Matsuda } \\
\text { [20] }\end{array}$ & 2012 & Hip arthroscopy & $2(1)$ & $1 / 2$ & $\begin{array}{l}\text { Case report of a patient with bilateral hip protrusio and } \\
\text { arthroscopic treatment; both hips were treated with } \\
\text { acetabuloplasty, femoroplasty, and labral refixation in } \\
\text { one hip and labral reconstruction gracilis autograft in } \\
\text { the other hip; in short-term followup, both hips } \\
\text { showed decreased pain and improved function }\end{array}$ \\
\hline $\begin{array}{l}\text { Safran and } \\
\text { Epstein } \\
{[30]}\end{array}$ & 2013 & Hip arthroscopy & $4(3)$ & 2.5 & $\begin{array}{l}\text { Protrusio hips treated with arthroscopic acetabuloplasty } \\
\text { and partial labrectomy; all hips showed improved } \\
\text { function and decreased pain }\end{array}$ \\
\hline $\begin{array}{l}\text { Liechti } \\
\quad \text { et al. [18] }\end{array}$ & 2015 & $\begin{array}{l}\text { Periacetabular osteotomy and rim } \\
\text { trimming }\end{array}$ & NA & NA & $\begin{array}{l}\text { Finite element study evaluating stress patterns in hips } \\
\text { with protrusio, which show } 54 \% \text { increased stress on } \\
\text { the medial acetabulum compared with normal; } \\
\text { acetabular rim trimming resulted in a further increase } \\
\text { of } 28 \% \text { medial acetabular stress compared with } \\
\text { protrusio; in contrast, periacetabular osteotomy } \\
\text { resulted in a reduction of } 25 \%\end{array}$ \\
\hline
\end{tabular}

$\mathrm{NA}=$ not applicable PAO = periacetabular osteotomy .

differences in sex. No variation was found for body mass index, which should therefore not jeopardize our results. The lower preoperative Merle d'Aubigné-Postel score in the study group was not a negative predictor in our regression analysis. Matching was not attempted because this would have resulted in sample sizes too small to allow meaningful analysis. Second, aside from the Merle d'Aubigné score, we do not have any other patient-reported outcome measures for both groups preoperatively. Other clinical scores were not routinely acquired at the time of patient presentation. However, we assessed the HHS, the WOMAC, the SF-12 score, and the UCLA score for all patients at the time of latest followup, and they are reported to allow comparison with future studies reporting other treatment options for protrusio hips. Third, although there was no difference in the mean followup of the groups, we found a wider spread of the followup intervals for the protrusio group. However, this fact is taken into account by the Kaplan-Meier survivorship analysis, the log-rank test for comparison of the curves, and the Cox regression analysis.

Based on our series, only half of the patients presented with no conversion to THA, no progression of osteoarthritis, and a clinical result exceeding 14 points according to Merle d'Aubigné-Postel score. Comparison to the literature is not possible because survival rate, rate of conversion to THA, or progression of osteoarthritis have not been systematically reported for long-term or even midterm followup after surgical treatment for protrusio (Table 6). Survival of protrusio hips is clearly inferior to patients undergoing open correction for FAI in nonprotrusio cases (Fig. 2). There are several explanations for this fact. As mentioned, the slightly higher prevalence of preoperative osteoarthritis combined with the somewhat increased age at the time of presentation (Table 1) may predispose to this result. Another explanation might be that from a biomechanical perspective, acetabular rim trimming only addresses the dynamic FAI pathomechanism [18]. The pathologically increased size of the lunate surface in protrusio hips [40] can be addressed with this technique [18]. However, it does not address the medial overload of the joint, which is typically a result of the negatively tilted acetabular roof [18].

We found eight predictors for conversion to THA, progression of osteoarthritis, or a clinical result with a Merle d'Aubigné-Postel score $<15$. Five of these seven factors are inherently given at the time of first presentation: age older than 47 years, body mass index of $>25 \mathrm{~kg} / \mathrm{m}^{2}$, a Sharp angle [32] $<34^{\circ}$, radiographic osteoarthritis Grade 2 or higher according to Tönnis [46], and a preoperative lateral center-edge angle [52] of $>50^{\circ}$. Increased age and preoperative degenerative changes also have been found to be negative predictive factors after valgus intertrochanteric osteotomy for the treatment of hip protrusio [21, 29, 48]. In addition, decreased preoperative ROM also has been found as a negative predictive factor after intertrochanteric osteotomy [21] but not in the current study for acetabular rim trimming (Table 4). The preoperative negative predictive factors in the current study indicate that advanced preexisting osteoarthritis should be considered as a relative contraindication in middle-aged patients. Based on these results, it seems that a marked pathomorphology (given by a low Sharp angle and a high lateral center-edge angle) is associated with increased risk for conversion to THA, 
progression of osteoarthritis, or a clinical result with a Merle d'Aubigné-Postel score $<15$ (Fig. 4). Besides proper selection of the patients based on the mentioned predictors, only three factors can actively be influenced by the surgeon. These factors indicate undercorrection of the acetabulum and comprise the reduction of the lateral center-edge angle exceeding $40^{\circ}$, the reduction of the acetabular index less than -8 , and the reduction of posterior femoral head coverage exceeding 56\%. The importance of accurate and complete surgical correction is analogous to previous studies analyzing the mid- and longterm results for open surgical treatment of FAI [1, 38, 39].

The pattern of radiographic degeneration reflects the complex mechanism of pathology in protrusio hips. The typical medial joint space narrowing was the most frequent finding preoperatively, which may be the result of the medial joint overload [18]. This in turn is the consequence of the negatively tilted acetabular roof and the varus configuration of the proximal femur in protrusio hips [17, 18]. After rim trimming for the protrusio hips, the pattern of degeneration changed. The joint space narrowing now also involved the lateral part of the joint. Osteophyte formation increased both laterally and medially. This might indicate that with the proposed treatment, only certain pathomechanical aspects (such as the dynamic FAI conflict) can be addressed. In accordance with the current results, joint space narrowing in protrusio hips has been reported to be most frequent medially and posteroinferiorly [17].

A direct comparison of our surgical technique with other procedures to treat protrusio acetabuli is not possible as a result of the heterogeneity or even lack of reported clinical results of these procedures by others (Table 6). The most commonly proposed surgical treatment is an intertrochanteric valgus osteotomy and medialization of the proximal femur [17, 21, 29, 48, 49]. With this procedure, the static pressure of the medial part of the acetabulum can be reduced. However, this does not solve the dynamic problem of pincer-type FAI in these hips. It can even lead to an amplification of a potential conflict between the posteroinferior femoral head-neck junction and the posterior horn of the acetabulum $[17,18]$. This might explain the variability of reported results ranging from promising midterm results [21] to sobering results after short-term followup [12]. There is only one previous report [17] of open acetabular rim trimming and two case reports [20, 30] of a total of six cases with arthroscopic circumferential rim trimming. These results at a short followup (Table 6) could not show a clear benefit of surgical treatment in hips with protrusio.

At 10 years, approximately half of the hips did not convert to THA, showed no progression of osteoarthritis, or had a clinical result with a Merle d'Aubigné-Postel score of at least 15. The lack of the natural history of hips with protrusio
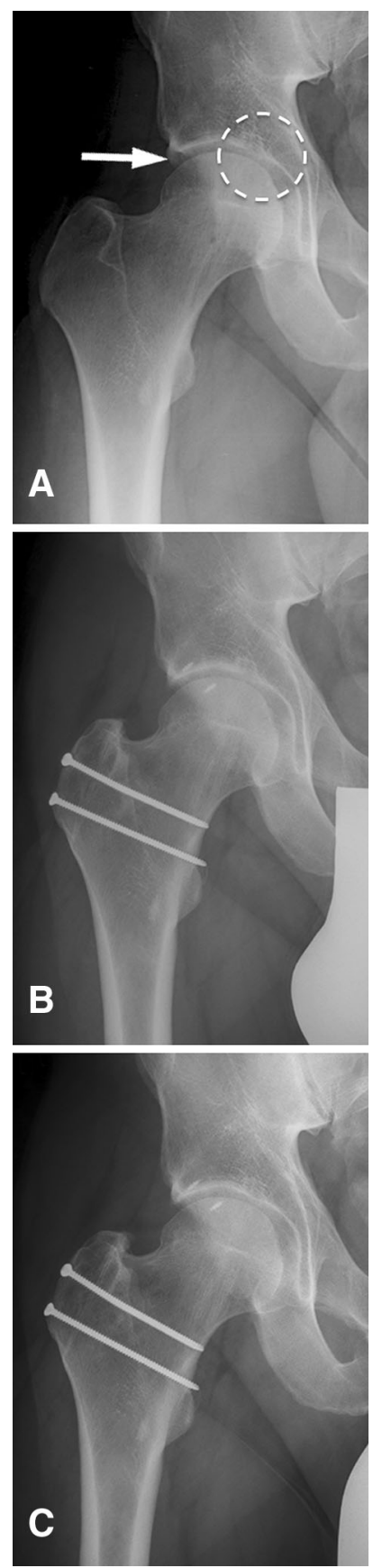

Fig. 5A-C Right hip of a 31-year-old man with pincer-type FAI with (A) preoperative cranial acetabular retroversion (arrow) and slight medial joint space narrowing (dotted circle). (B) He underwent surgical hip dislocation and trimming of the acetabular rim with labral reattachement. (C) At 10-year followup he presents with an unchanged medial joint space narrowing without further degeneration.

makes interpretation of these results difficult. Compared with classic pincer hips (Fig. 5), hips with protrusio showed a substantially reduced survival (51\% versus $83 \%)$. The optimal indication for rim trimming in protrusio would be a young patient (age $<47$ years) with no or only minor joint 
degeneration (Tönnis Grade 1 or less) and not overweight (body mass index $<25 \mathrm{~kg} / \mathrm{m}^{2}$ ). In the most severe forms of protrusio (lateral center-edge angle $>50^{\circ}$ or Sharp angle $<34^{\circ}$ ) or without sufficient trimming, the likelihood to survive 10 years was clearly reduced. Even with optimal indications, isolated rim trimming may not resolve the pathomorphology in protrusio hips given the clearly inferior results compared with surgical hip dislocation for FAI without severe overcoverage.

\section{References}

1. Albers CE, Steppacher SD, Ganz R, Tannast M, Siebenrock KA. Impingement adversely affects 10 -year survivorship after periacetabular osteotomy for DDH. Clin Orthop Relat Res. 2013;471:1602-1614.

2. d'Aubigné RM, Postel M. Functional results of hip arthroplasty with acrylic prosthesis. J Bone Joint Surg Am. 1954;36:451-475.

3. Bellamy N, Buchanan WW, Goldsmith $\mathrm{CH}$, Campbell J, Stitt LW. Validation study of WOMAC: a health status instrument for measuring clinically important patient relevant outcomes to antirheumatic drug therapy in patients with osteoarthritis of the hip or knee. J Rheumatol. 1988;15:1833-1840.

4. Brückl L. [Congenital deformity of the hip joint] [in German] In: Jäger M, Wirth CJ, ed. Praxis der Orthopädie. Stuttgart, Germany: Georg Thieme Verlag; 1998.

5. Cox R. Regression models and life tables. J R Stat Soc B. 1972;34:187-220.

6. Dunlop CCR, Jones CW, Maffulli N. Protrusio acetabuli. Bull Hosp Jt Dis. 2005;62:105-114.

7. Espinosa N, Rothenfluh DA, Beck M, Ganz R, Leunig M. Treatment of femoro-acetabular impingement: preliminary results of labral refixation. J Bone Joint Surg Am. 2006;88:925-935.

8. Ferguson SJ, Bryant JT, Ganz R, Ito K. An in vitro investigation of the acetabular labral seal in hip joint mechanics. $J$ Biomech. 2003;36:171-178.

9. Gandek B, Ware JE, Aaronson NK, Apolone G, Bjorner JB, Brazier JE, Bullinger M, Kaasa S, Leplege A, Prieto L, Sullivan M. Cross-validation of item selection and scoring for the SF-12 Health Survey in nine countries: results from the IQOLA Project. International Quality of Life Assessment. J Clin Epidemiol. 1998;51:1171-1178.

10. Ganz R, Gill TJ, Gautier E, Ganz K, Krügel N, Berlemann U. Surgical dislocation of the adult hip a technique with full access to the femoral head and acetabulum without the risk of avascular necrosis. J Bone Joint Surg Br. 2001;83:1119-1124.

11. Harris WH. Traumatic arthritis of the hip after dislocation and acetabular fractures: treatment by mold arthroplasty. An end-result study using a new method of result evaluation. J Bone Joint Surg Am. 1969;51:737-755.

12. Hooper JC, Jones EW. Primary protrusion of the acetabulum. $J$ Bone Joint Surg Br. 1971;53:23-29.

13. Idelberger K, Frank A. [A new method for determination of the angle of the pelvic acetabulum in child and in adult] [in German]. Z Orthop Ihre Grenzgeb. 1952;82:571-577.

14. Kalberer F, Sierra RJ, Madan SS, Ganz R, Leunig M. Ischial spine projection into the pelvis: a new sign for acetabular retroversion. Clin Orthop Relat Res. 2008;466:677-683.

15. Kaplan EL, Meier P. Nonparametric estimation from incomplete observations. J Am Stat Assoc. 1958;53:457-481.

16. Larson CM, Giveans MR, Stone RM. Arthroscopic débridement versus refixation of the acetabular labrum associated with femoroacetabular impingement: mean 3.5-year follow-up. Am J Sports Med. 2012;40:1015-1021.

17. Leunig M, Nho SJ, Turchetto L, Ganz R. Protrusio acetabuli: new insights and experience with joint preservation. Clin Orthop Relat Res. 2009;467:2241-2250.

18. Liechti EF, Ferguson SJ, Tannast M. Protrusio acetabuli: joint loading with severe pincer impingement and its theoretical implications for surgical therapy. J Orthop Res. 2015;33:106113.

19. Martin RL, Sekiya JK. The interrater reliability of 4 clinical tests used to assess individuals with musculoskeletal hip pain. $J$ Orthop Sports Phys Ther. 2008;38:71-77.

20. Matsuda DK. Protrusio acetabuli: contraindication or indication for hip arthroscopy? And the case for arthroscopic treatment of global pincer impingement. Arthroscopy. 2012;28:882-888.

21. McBride MT, Muldoon MP, Santore RF, Trousdale RT, Wenger DR. Protrusio acetabuli: diagnosis and treatment. J Am Acad Orthop Surg. 2001;9:79-88.

22. McWhirk LB, Glanzman AM. Within-session inter-rater realiability of goniometric measures in patients with spastic cerebral palsy. Pediatr Phys Ther. 2006;18:262-265.

23. Mofidi A, Shields JS, Stubbs AJ. Central acetabular osteophyte (saber tooth sign), one of the earliest signs of osteoarthritis of the hip joint. Eur J Orthop Surg Traumatol. 2010;21:71-74.

24. Murphy SB, Ganz R, Müller ME. The prognosis in untreated dysplasia of the hip. A study of radiographic factors that predict the outcome. J Bone Joint Surg Am. 1995;77:985-989.

25. Naal FD, Miozzari HH, Schär M, Hesper T, Nötzli HP. Midterm results of surgical hip dislocation for the treatment of femoroacetabular impingement. Am J Sports Med. 2012;40: 1501-1510.

26. Nötzli HP, Wyss TF, Stoecklin CH, Schmid MR, Treiber K, Hodler J. The contour of the femoral head-neck junction as a predictor for the risk of anterior impingement. J Bone Joint Surg Br. 2002;84:556-560.

27. Philippon MJ, Briggs KK, Yen Y-M, Kuppersmith DA. Outcomes following hip arthroscopy for femoroacetabular impingement with associated chondrolabral dysfunction: minimum two-year follow-up. J Bone Joint Surg Br. 2009;91:16-23.

28. Reynolds D, Lucas J, Klaue K. Retroversion of the acetabulum. A cause of hip pain. J Bone Joint Surg Br. 1999;81:281-288.

29. Rosemeyer B, Viernstein K, Schumann HJ. [Follow up study of intertrochanteric valgus osteotomy with medial displacement in cases of primary protrusio acetabuly (author's transl)] [in German]. Arch Orthop Unfallchir. 1973;77:138-148.

30. Safran MR, Epstein NP. Arthroscopic management of protrusio acetabuli. Arthroscopy. 2013;29:1777-1782.

31. Scandalis R, Ghormley RK, Dockerty MB. Arthrokatadysis (Otto pelvis). Surgery. 1951;29:255-259.

32. Sharp IK. Acetabular dysplasia: the acetabular angle. $J$ Bone Joint Surg Br. 1961;43:268-272.

33. Sierra RJ, Trousdale RT. Labral reconstruction using the ligamentum teres capitis: report of a new technique. Clin Orthop Relat Res. 2009;467:753-759.

34. Skendzel JG, Philippon MJ, Briggs KK, Goljan P. The effect of joint space on midterm outcomes after arthroscopic hip surgery for femoroacetabular impingement. Am $J$ Sports Med. 2014;42:1127-1133.

35. Smith-Petersen MN. The classic: Treatment of malum coxae senilis, old slipped upper femoral epiphysis, intrapelvic protrusion of the acetabulum, and coxa plana by means of acetabuloplasty. 1936. Clin Orthop Relat Res. 2009;467:608-615.

36. Solomon L. Patterns of osteoarthritis of the hip. J Bone Joint Surg Br. 1976;58:176-183.

37. Steel HH. Protrusio acetabuli: its occurrence in the completely expressed Marfan syndrome and its musculoskeletal component 
and a procedure to arrest the course of protrusion in the growing pelvis. J Pediatr Orthop. 1996;16:704-718.

38. Steppacher SD, Anwander H, Zurmühle CA, Tannast M, Siebenrock KA. Eighty percent of patients with surgical hip dislocation for femoroacetabular impingement have a good clinical result without osteoarthritis progression at 10 years. Clin Orthop Relat Res. 2015;473:1333-1341.

39. Steppacher SD, Huemmer C, Schwab JM, Tannast M, Siebenrock KA. Surgical hip dislocation for treatment of femoroacetabular impingement: factors predicting 5-year survivorship. Clin Orthop Relat Res. 2014;472:337-348.

40. Steppacher SD, Lerch TD, Gharanizadeh K, Liechti EF, Werlen SF, Puls M, Tannast M, Siebenrock KA. Size and shape of the lunate surface in different types of pincer impingement: theoretical implications for surgical therapy. Osteoarthritis Cartilage. 2014;22:951-958.

41. Tannast M, Hanke MS, Zheng G, Steppacher SD, Siebenrock KA. What are the radiographic reference values for acetabular under- and overcoverage? Clin Orthop Relat Res. 2015;473: 1234-1246.

42. Tannast M, Leunig M, Session Participants. Report of breakout session: Coxa profunda/protrusio management. Clin Orthop Relat Res. 2012;470:3459-3461.

43. Tannast M, Mistry S, Steppacher SD, Reichenbach S, Langlotz F, Siebenrock KA, Zheng G. Radiographic analysis of femoroacetabular impingement with Hip2Norm-reliable and validated. $J$ Orthop Res. 2008;26:1199-1205.

44. Tannast M, Siebenrock KA, Anderson SE. Femoroacetabular impingement: radiographic diagnosis-what the radiologist should know. AJR Am J Roentgenol. 2007;188:1540-1552.

45. Tannast M, Zheng G, Anderegg C, Burckhardt K, Langlotz F, Ganz R, Siebenrock KA. Tilt and rotation correction of acetab- ular version on pelvic radiographs. Clin Orthop Relat Res. 2005;438:182-190.

46. Tönnis D. General radiography of the hip joint. In: Tönnis D, ed. Congenital Dysplasia and Dislocation of the Hip. Heidelberg, Germany: Springer-Verlag; 1987.

47. Tönnis D, Heinecke A. Acetabular and femoral anteversion: relationship with osteoarthritis of the hip. J Bone Joint Surg Am. 1999;81:1747-1770.

48. Verburg A, Elzenga P. Intertrochanteric valgization osteotomy for treatment of primary protrusion of the acetabulum (OttoChrobak pelvis). Arch Chir Neerl. 1978;30:207-215.

49. Viernstein K, Rosemeyer B, Hennig A. [A possibility for the surgical therapy of acetabular protrusion] [in German]. Arch Orthop Unfallchir. 1970;67:291-302.

50. Ware J, Kosinski M, Keller SD. A 12-Item Short-Form Health Survey: construction of scales and preliminary tests of reliability and validity. Med Care. 1996;34:220-233.

51. White BJ, Herzog MM. Labral reconstruction: when to perform and how. Front Surg. 2015;2:27.

52. Wiberg G. The anatomy and roentgenographic appearance of a normal hip joint. Acta Chir Scand. 1939;83:7-38.

53. Wyss TF, Clark JM, Weishaupt D, Nötzli HP. Correlation between internal rotation and bony anatomy in the hip. Clin Orthop Relat Res. 2007;460:152-158.

54. Zahiri CA, Schmalzried TP, Szuszczewicz ES, Amstutz HC. Assessing activity in joint replacement patients. J Arthroplasty. 1998;13:890-895.

55. Zheng G, Tannast M, Anderegg C, Siebenrock KA, Langlotz F. Hip2Norm: an object-oriented cross-platform program for 3D analysis of hip joint morphology using 2D pelvic radiographs. Comput Methods Programs Biomed. 2007;87:36-45. 